\title{
Malaria and the Sickle Gene: Polymorphism Balance in favour of eradication \\ Olatunji PO
}

Department of Haematology and Blood Transfusion, Obafemi Awolowo College of Health Sciences, Olabisi Onabanjo University, Sagamu, Nigeria.

Correspondence: Professor PO Olatunji, Department of Haematology and Blood Transfusion, Obafemi Awolowo College of Health Sciences, Sagamu, Ogun State, Nigeria.

E-mail: poolatunji@yahoo.com; ORCID - http://orcid.org/0000-0002-3623-8972.

\section{Summary}

Evolutionally, the single nucleotide mutation responsible for the sickle haemoglobin gene, (HbS gene) developed from the regions of the world where malaria is holoendemic, leading to the explanation that the mutation is in response to the presence of the malaria parasite. Studies eventually showed that individuals that are heterozygous for the HbS gene are protected from the lethal clinical effects of malaria infection. In other words, malaria confers a survival advantage to carriers of the HbS gene, and this is referred to as balanced polymorphism. On the other hand, malaria infection is associated with significant morbidity and mortality, particularly among children. Unfortunately, lack of success in the effort to eradicate the malaria parasite through the elimination of the Anopheles mosquito or efforts to limit its contact with human being has produced little success, hence the resort to roll back malaria, with the aim of reducing the morbidity and mortality associated with it.

Therefore, it is attractive to consider what will happen to the sickle gene if malaria were to be eradicated. That is, the possibility is that the sickle gene may also follow suit since its evolution in the first instance was as a response to malaria., This is the hypothesis being propounded by this article. In that case, rather than shy away from the malaria eradication initiative, it should remain the goal of all malaria programs.

Keywords: Balanced polymorphism, Eradication, Malaria, Plasmodium, Sickle cell gene, Sickle cell haplotypes.

\section{Introduction}

Malaria infection is caused by the protozoan organism, Plasmodium, of which there are four main species i.e.falciparum, vivax, malariae and ovale. The most deadly and most prevalent species in areas of holoendemicity, including Nigeria, is Plasmodium falciparum. ${ }^{[1,2] \text { Although }}$ death from malaria has been reduced significantly by $40-50 \%$ as a result of the global efforts at malaria control through effective case management, insecticide-treated bed nets, vector control, and chemoprevention, it is estimated that a child still dies from malaria every minute in sub-Saharan Africa. [3] The life cycle of $P$. falciparum malaria infection (Figure 1) involves a vector, the female Anopheles mosquito, in which fertilization of the parasite takes place and the human host, in whom the parasite goes through the liver phase followed by the erythrocytic phase. The life cycle continues with the production of merozoites, which are largely responsible for the symptoms and immunologic reactions, and 


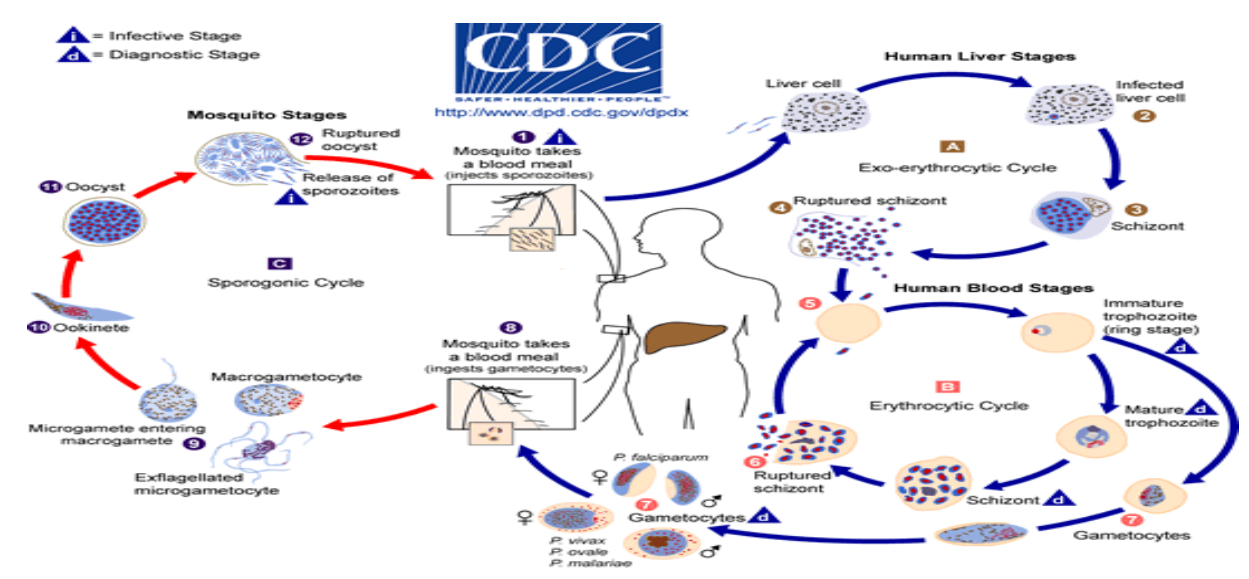

Figure 1: Life Cycle of the Malaria Parasite [4]

There are at least, three main clinical consequences of malaria infection. These consequences include the fever and chills resulting from the reaction to malaria antigens, anaemia caused by intravascular haemolysis and extra-vascular haemolysis resulting from sequestration of parasitized and non-parasitized red blood cells. [5] The third consequence is the adhesion of red cells to the vascular endothelium (cytoadherence) leading to the narrowing and obstruction of small blood vessels and diminution of blood flow to, and dysfunction of vital organs including the brain. [6,7]

The term 'falciparum' given to this most deadly species of Plasmodium and which is prevalent in Nigeria, is derived from two Latin words 'falce' and 'parum' meaning, 'crescent or sickle' and 'very small', respectively. In other words, falciparum can be translated to mean 'very little sickle. ${ }^{[8]}$ The similarity in the shape of the parasite gametocyte and the sickle red cell may appear coincidental, but the similarity of cytoadherence and the complementary nature of the pathology and clinical outcome of both diseases are striking.

\section{The Sickle Gene}

The earliest documentation of the sickling phenomenon was made by James B Herrick, [9] who observed peculiar elongated red blood cells in the peripheral blood film of a black American in 1904 and reported it in literature in 1910. The term 'sickle cells' was first used by Mason, $\left.{ }^{[10}\right]$ to describe the end product of precipitation, polymerization, stacking, the formation of tactoid of sickle haemoglobin $(\mathrm{Hb}$ S) under reduced oxygen tension and eventual change in shape of the red blood cell to the form of a crescent. [11-,16]

The work of Ingram [17] in 1956 showed that the abnormality in sickle haemoglobin was due to the replacement of Glutamic acid by Valine at the sixth amino-acid position in the $\beta$-globin peptide chain. This replacement follows a single point mutation in codon 6 , in which Adenine replaces Thymine $(\mathrm{GAG} \rightarrow \mathrm{GTG})$ in the DNA on the $\beta$-globin chain locus in the short arm of chromosome 11. Uracil replaced Adenine (GAG $\rightarrow \mathrm{GUG})$ in the RNA. However, further research discovered other genetic factors affecting the clinical expression and severity of sickle cell disease, including those linked to the $\beta$ globin 
gene, as well as those linked to the other gene loci. These are referred to as epigenetic factors.

The globin gene is inherited is by simple Mendelian fashion of a recessive gene. The pathophysiologic mechanisms underlying the clinical syndrome include: sickling of red blood cells in the homozygous state, intra- and extra-vascular haemolysis, adhesion of cells to the vascular endothelium, thickening of the vessel wall due to reduction in Nitric Oxide production, occlusion of small and large vessels and increase in the levels of thrombogenic substances. All these factors contribute to vaso-occlusion, infarction, and fibrosis of several organs of the body, with attendant pain and loss of function. The resultant clinical syndrome consists of recurrent pain episodes or varying severity, chronic anaemia, organ failures, stroke, and susceptibility to infections, particularly the pneumococcus. The complications include chronic leg ulcers, gallstones, priapism, avascular necrosis of femoral or humeral heads, chronic osteomyelitis, retinopathies, stroke and reduced survival. Recognised indices of severity of sickle cell anaemia include frequency of crises, number of transfusions per year, level of Haemoglobin $\mathrm{F}$ $(\mathrm{HbF})$, the degree of persistent hepatomegaly or splenomegaly, and the number of chronic complications. Epigenetic modulators of clinical course, severity and survival are made up of environmental and socio-economic factors, the level of $\mathrm{Hb} \mathrm{F}$, cluster around the $\mathrm{X}$ chromosomes, gene cluster haplotypes and coinheritance of a-Thalassaemia. ${ }^{[18,19]}$ The most proven genetic modulators are genes and factors determining the level of $\mathrm{Hb} \mathrm{F}$ and $\beta^{s}$ gene cluster haplotypes.[20 - 26]

Studies on $\beta^{5}$ gene cluster haplotypes show that the sickle mutation must have taken place independently in at least five epicentres in Africa and Arabia. The five clusters are called haplotypes and these consist of Benin, Central African (Bantu), Cameroon, Senegal, and Arab Haplotypes. The clinical course of Sickle Cell
Anaemia is influenced by the haplotype pattern, with the most severe clinical course being associated with the Benin and the Bantu Haplotypes, while the Arab and Senegal Haplotypes are associated with a milder clinical course. This makes the sickling phenomenon and the accompanying disease African in origin and epidemiology. It is known that the mild clinical course associated with the Arab Haplotypes is modulated by the high level of $\mathrm{Hb} \mathrm{F}$ resulting from Hereditary Persistence of Foetal Haemoglobin (HPFH). [12,13] This forms the basis for the therapeutic use of agents such as hydroxyurea, which is known to increase the level of $\mathrm{Hb} \mathrm{F}$ and reduce the degree of haemolysis. However, haemopoietic stem cell transplantation remains the only known curative intervention in sickle cell disease.

\section{Balanced Polymorphism}

Genetic Polymorphism refers to the ability of a gene locus to exist in two different alleles within the same population, each with a minimum frequency of not less than $1 \%$. Due to the sickle gene mutation, the $\beta$ globin gene is able to exist in the $\beta^{\mathrm{A}}$ and $\beta^{\mathrm{S}}$ forms in the population. Therefore, it is possible for the gene to exist in the heterozygous (AS) and homozygous (SS) forms in the population. Since the sickle mutation occurred in the same population with high prevalence of Plasmodium falciparum infection and lethal form of malaria, particularly in children, it was postulated that the mutation arose as a form of protection against the lethal form of infection. This appears to be in tandem with earlier postulation by Haldane [27] that Thalassaemia could offer protection against lethal malaria. The presence of sickle haemoglobin in heterozygotes reduces the effect of the malaria parasite and creates a survival advantage, while the homozygotes (AA or SS) remain more susceptible. This is what is known as Balanced Polymorphism. 
Apart from balanced polymorphism, there are fortuitous striking similarities and complementarities between the malaria parasite and the sickled erythrocyte. Firstly, they both derive their names from Latin and English words for sickle or crescent. The crescent or sickle shape of the malaria parasite is represented by the gametocyte.

Both parasitized erythrocytes and sickled erythrocytes are susceptible to removal by the reticuloendothelial system of the body. Parasitized erythrocyte and sickled erythrocytes exhibit cytoadherence with resultant narrowing of the vascular channels. The acidosis produced by the malaria parasite can induce sickling of the heterozygote red blood cells. Consequently, the presence of the malaria parasite does complement sickling and vaso-occlusion. This is why the homozygous sickle cell anaemia patient is susceptible to malaria infection through the worsening the degree of anaemia, precipitation of crises, and development of further complications in an environment of functional hyposplenia. Indeed, before the discovery of antimalarial drugs and antibiotics, it was difficult to find patients with sickle cell anaemia in developing countries of Africa since nearly all of them died of malaria and bacterial infections. This led to the initial erroneous impression that sickle cell anaemia was only found in black Americans as cases were not diagnosed in Africa until about twenty years after Herrick.

- Paradoxically, the sickle gene is protective against lethal effect of malaria in those who are heterozygote. Through the studies of Allison [28] and others, it had been established that those who are heterozygote for the A and S globin genes have lower parasite load when they have malaria, have a lower incidence of severe or cerebral malaria and have reduced mortality rate. This confers a survival advantage on them with the ability to continue the transmission of the Haemoglobin $\mathrm{S}$ gene. The mechanism of this protection has been a subject of study over the years. Continuing studies have identified the following mechanisms: removal of parasitized erythrocyte, either sickled or normal shaped by the reticuloendothelial system i.e. extra-vascular haemolysis (Figure 4) leading to a reduction in parasite load in the patient. [29-31]

- The disruption of parasite growth and survival through inability to adequately metabolize sickle haemoglobin; Reduced cytoadherence by AS parasitized red blood cells due to altered display on the red cell surface of the P.falciparum erythrocyte membrane protein 1 (PfEMP-1) and leading to reduction in the incidence of cerebral malaria.

- Accelerated acquisition of innate and acquired immunity by the AS heterozygotes.

The most recent mechanism was highlighted by the study of Ana Ferreira ${ }^{[32,33]}$ who initially found that $\mathrm{Hb} \mathrm{AS}$ individuals are protected from developing cerebral malaria through its effect on haeme, and that carbon monoxide (CO) also protected mice from developing cerebral malaria through reduction in the amount of haeme. Later studies showed that the protection was mediated through the induction of expression of the enzyme Haeme Oxygenaae-1 (HO-1) with the production of $\mathrm{CO}$ (Figures 2 and 3). The expression of Haeme Oxygenase (HO-1) is induced by free haeme, through a mechanism that involves the transcription factor NF-E2-related factor-2 (Nrf2). Upon nuclear translocation, Nrf2 binds to the stress-responsive elements in the Hmox1 promoter, a regulatory mechanism that plays a central role in the control of Hmox 1 expression in response to haeme. This 
binding up-regulates the expression HO-1 which catalyzes the catabolism of haeme with the production of Carbon Monoxide (CO)

(Figure 4).
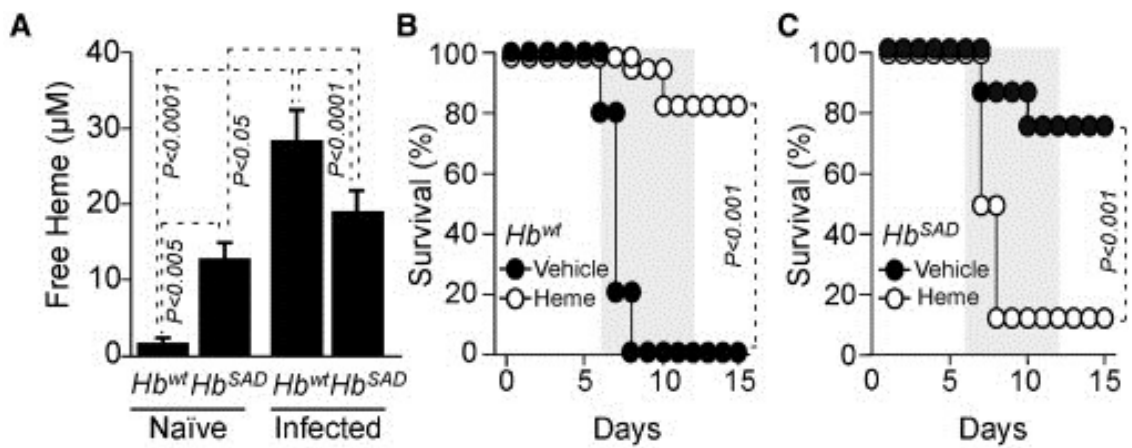

Figure 2: Effect of S Haemoglobin on Haeme and Survival in $\mathrm{Hb}$ AS mice ${ }^{32}$

Carbon monoxide prevents further haeme release from the cell-free $\mathrm{Hb}$ after Plasmodium infection, thus suppressing the pathogenesis of experimental Cerebral Malaria (ECM). Moreover, sickle human $\mathrm{Hb}$ exerts an immunoregulatory effect that appears to act independently of Nrf2 and/or HO-1. This is achieved by suppression of Antigen Presenting Cells in a way that inhibits cytotoxic CD8+ $\mathrm{T}$ cells (TC) activation and expansion and reduces the expression of cytokines Figure 5.
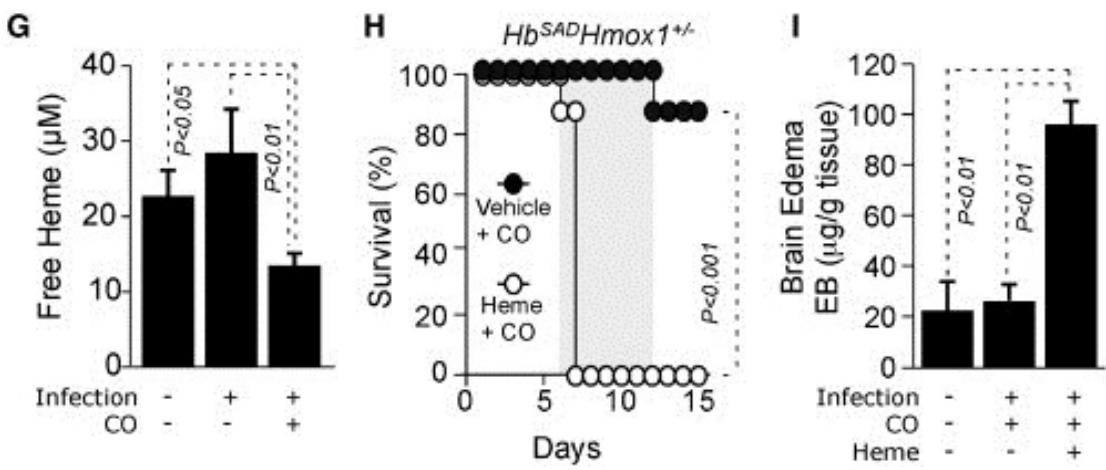

Figure 3: Effect of Carbon Monoxide (CO) on Free Haeme and Brain Oedema ${ }^{32}$

Haeme is also known to induce the activation of the coagulation system through the release of Tissue Factor. The reduction in the level of Haeme through conversion to Carbon monoxide will, in turn, reduce the release of Tissue Factor and reduce the activation of the coagulation system. It must be noted that this study was carried out in sickle cell mice infected with $P$. berghei, which is different from $P$. falciparum.

\section{Maintaining or Tilting the Polymorphism Balance}

Balanced Polymorphism produces winwin-no lose situation for the sickle gene, the heterozygote AS individual and the malaria parasite. The $S$ gene propagates 
itself through the survival advantage afforded the heterozygote, while the ability of the malaria parasite to infect remains

unchanged.

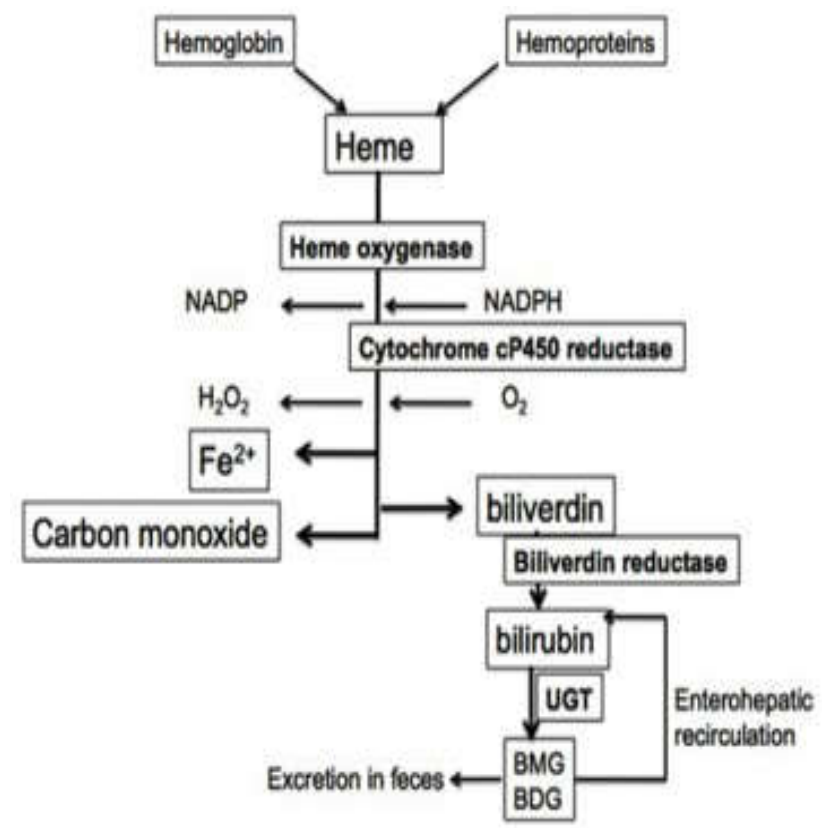

Figure 4: Haeme Metabolism

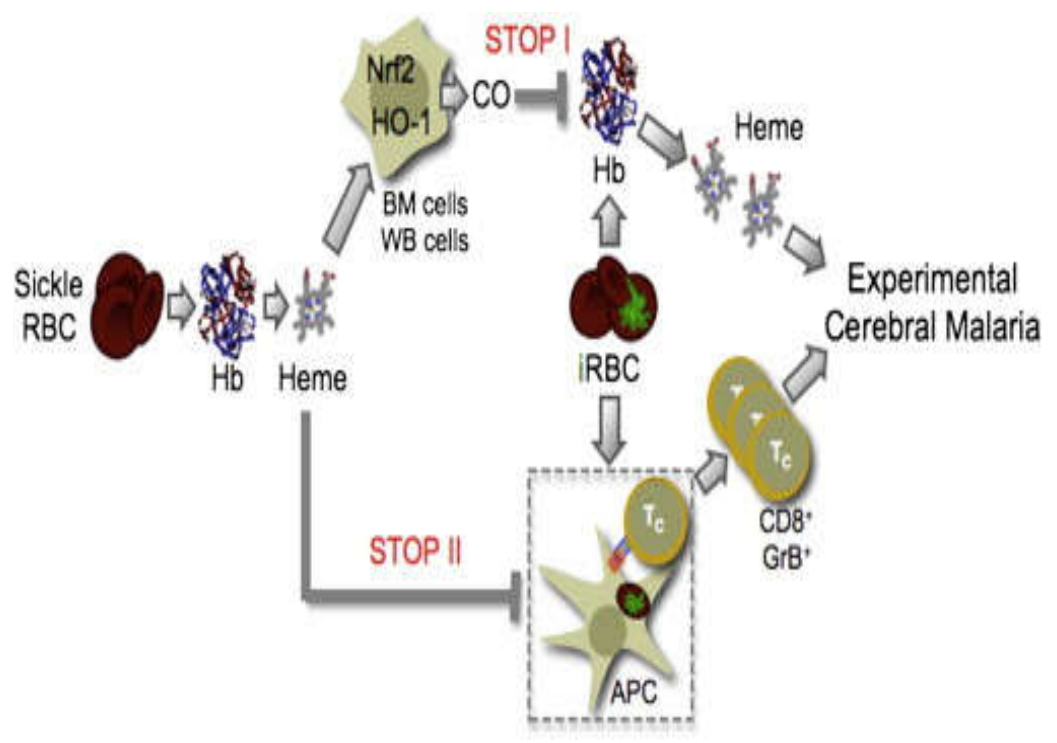

Figure 5: Induction of HO-1 in HbAS mice and Experimental Cerebral Oedema [32]

For the homozygous AA or SS, survival is reduced through susceptibility to lethal effects of malaria infection in the AA individual or severe clinical course or death through severe anaemia and other complications for the SS individual. Consequently, the world is committed to the eradication of both the sickle (S) gene and falciparum malaria. Nonetheless, 
the continued partnership and marriage between individuals with $\mathrm{Hb} \mathrm{S}$ and the environmental difficulty in controlling the malaria parasite vector, the Anopheles mosquito continue to make the eradication of either case a major challenge. What is not being discussed is the effect of the eradication of one or the other on the polymorphism balance.

In considering the possibility of eradicating the sickle gene without malaria eradication:

Everybody will be homozygous AA and be susceptible to lethal effects of malaria infection, especially children, in whom mortality will be high unless something occurs again to produce amelioration or the socioeconomic and health care situation improve to counter the effects. The cost of treating malaria will escalate in a depressed economy. Therefore, the balance tilts in favour of the malaria parasite. If on the other hand malaria was eradicated but the efforts to prevent continued reproductive partnership between heterozygotes and transmission of sickle gene fails, the balance will tilt in favour of the $S$ gene.

Heterozygotes will lose their survival advantage and homozygotes will experience improved survival as death through malaria infection will be eliminated. The socioeconomic, psycho-social, and cost implications of caring for an increased number of homozygous $\mathrm{S}$ individuals will increase. It is, however, arguable that whatever the cost increase, it is still preferable to manage one of these two disorders rather than both, meaning that the eradication of at least one of them is desirable.

\section{The Final Hypothesis}

Given the enduring balance and interrelationship between the sickle gene and malaria and the depth of understanding of the epidemiology, molecular biology, pathophysiology, and clinical course of both sickle cell disease and malaria, the eradication of one may also terminate the other. Which one should the world expend energy to eradicate?

It is attractive to hypothesize that if the sickle gene were to be eradicated in the presence of malaria in Africa, another epicentre will emerge again to select the sickle or any other gene in response to the lethal effects of malaria. If on the other hand, malaria eradication becomes a reality, the process of natural selection will eliminate the sickle gene, and in the absence of the malaria pressure, the need for mutation producing new or propagating old abnormal haemoglobin will not exist.

Therefore, the eradication of malaria will lead to de-selection of the sickle gene and result in its ultimate eradication. It is hoped that this hypothesis will further promote the quest for malaria eradication without termination of the current efforts aimed at reducing or stopping the transmission of the sickle gene through genetic counselling, screening and prenatal diagnosis.

\section{Conclusion}

Apart from the clinical consequences of malaria infection and the huge cost of health services and treatment, another compelling reason for continuing effort at malaria eradication is the possibility that it holds the key to decline in the propagation, and probable long-term eradication of abnormal haemoglobin genes in the black population.

\section{References}

1. National Institute of Health (NIH). Understanding malaria: fighting an ancient scourge. U.S. Department of Health and Human Services. 2007. Available 
http://www.niaid.nih.gov/publications/ malaria/pdf/malaria.pdf. Accessed 27th August 2015

2. Akande TM, Musa IO: Epidemiology of Malaria in Africa. Afr J Clin Exp Microbiol 2005; 6(2): 107-11.

3. WHO: Global Health Observatory Data Malaria. Fact Sheet No. 94, April 2015.

4. Centers for Disease Prevention and Control (CDC). Schema of the life cycle of malaria. 2006. Available at http://www.cdc.gov/malaria/biology/lif e_cycle.htm. Accessed 9th February 2007.

5. Manning L, Laman M, Davis WA, Davis TME. Clinical features and outcome in children with severe Plasmodium falciparum malaria: A Meta-Analysis. PLoS ONE 2004; 9(2): e86737. doi:10.1371/journal.pone.0086737.

6. Wikipedia: Plasmodium falciparum. https://en.wikipedia.org/w/index.php?ti tle=Plasmodium_falciparum\&oldid $=67303$ 6356.

7. Snow RW. Global malaria eradication and the importance of Plasmodium falciparum epidemiology in Africa. BMC Med 2015; 13:23. doi:10.1186/s12916-0140254-7.

8. Wiktionary: Definition of 'falciparum'. https://en.wiktionary.org/wiki/falciparu $\mathrm{m}$

9. Herrick, JB. Peculiar, elongated, sickleshaped red blood corpuscles in a case of severe anaemia. Arch Int Med 1910; 6: 517-21.

10. Mason VR. Sickle cell anemia. J Am Med Assoc 1922; 79: 1318-20.

11. Bainbridge R, Higgs DR, Maude GH, Serjeant GR. Clinical presentation of homozygous sickle cell disease. J Paediatr 1985; 106: 881-5.
12. Beet EA. The genetics of the sickle-cell trait in a Bantu tribe. Ann Eugenics 1949; 14: 279-84.

13. Kan YW, Dozy AM. Evolution of the Hemoglobin S and C Genes in World Populations. Science 1980; 209: 388-91.

14. Kan YW, Dozy AM: Polymorphism of DNA sequence adjacent to human $\beta$ globin structural gene: Relationship to sickle mutation. Proc Natl Acad Sci 1978; 75: 5631-5.

15. Murayama M. Molecular mechanism of red cell "sickling". Science 1966; 153: 145-9.

16. Neel JV. The inheritance of sickle cell anemia. Science 1949; 110: 64-6.

17. Ingram VM. A specific chemical difference between the globins of normal human and sickle cell haemoglobin. Nature 1956; 178: 972-4.

18. Attah EB. The pathology of sickle cell disease In: Fleming AF (Ed). Sickle-cell Disease; A Handbook for the General Clinician. Churchill Livingstone. Edinburgh, London, Melbourne and New York,.1982: pp 42-56.

19. Higgs DR, Aldridge BE, Lamb J, Glegg JB, Weatheral DJ, et al The Interaction of Alpha-Thalassemia and Homozygous Sickle-Cell Disease. New Engl J Med 1982; 306: 1441-6.

20. Powars D, Chan LS, Schroeder WA. The Variable Expression of Sickle Cell Disease is genetically determined. Semin Hematol; 1990; 27: 360-76.

21. Powars D, Weidman JA, Odom-Maryon T, Niland JC, Johnson C. Sickle Cell Chronic Lung Disease: Prior Morbidity and the Risk of Pulmonary Failure. Medicine 1988; 67: 66-76.

22. Powars D. Sickle Cell Anemia: $\beta^{5}$-GeneCluster Haplotype as Prognostic Indicators of Vital Organ Failure. Semin Hematol 1991; 28: 202-8. 
23. Powars DR, Weiss JN, Chan LS, Schroeder WA. Is there a threshold Level of Fetal Hemoglobin that ameliorates morbidity in Sickle Cell Anemia? Blood 1984; 63: 921-6.

24. Falusi AG, Olatunji PO. Effect of alpha thalassaemia and haemoglobin $\mathrm{F}(\mathrm{HbF})$ level on the clinical severity of sickle cell anaemia. Eur J Haematol 1994; 52: 13-5.

25. Olatunji AA, Olatunji PO. Splenic size determination in Sickle Cell Anaemia: An Ultrasonographic Study. East Afr Med J 2001; 78: 26-9.

26. Olatunji PO, Davies SC, Dore C, Old JM. Influence of Gender and Senegal Haplotype on the amelioration of the clinical severity in Sickle Cell Anaemia. Niger Postgrad Med J 2000; 7: 5-9.

27. Haldane JBS. Disease and evolution. Ricerca Sci.1949; 19(Suppl I): 68-76.

28. Allison AC. Protection afforded by sickle cell trait against subtertian malaria infection. Br Med J 1954; 1: 290-4.
29. Luzzatto L. Genetics of red cells and susceptibility to malaria. Blood 1979; 54: 961-76.

30. Luzzatto L. Sickle Cell Anaemia and Malaria. Mediterr J Hematol Infect Dis 2012; 4(1): e2012065.

31. Ayi K, Turrini F, Piga A, Arese P. Enhanced phagocytosis of ring-parasitized mutant erythrocytes: a common mechanism that may explain protection against falciparum malaria in sickle trait and beta-thalassemia trait. Blood 2004; 104: 3364-71.

32. Ferreira A, Marguti I, Bechmann I, Jeney V, Chora A, Palha NR, et al. Sickle hemoglobin confers tolerance to Plasmodium infection. Cell 2011; 145: 398409. http://dx.doi.org/10.1016/j.cell.2011. 03.049 .

33. Instituto Gulbenkian de Ciencia. Mystery solved: How sickle hemoglobin protects against malaria. Science Daily. Available at:

www.sciencedaily.com/releases/2011/04 /110428123931.htm. Accessed 27th July 2015. 